\title{
Pelapisan Kalsium Karbida Permukaan Baja Karbon Rendah dengan Pack Carburizing Energizer Serbuk Cangkang Kerang Mutiara
}

\author{
Sujita Darmo*, Sugiman, Salman, Agus Dwi Catur, Paryanto Dwi Setyawan \\ Jurusan Teknik Mesin, Universitas Mataram \\ *Email: sujita@unram.ac.id
}

Received: 23 September 2020; Accepted: 5 Desember 2020; Published: 14 Desember 2020 DOI: http://dx.doi.org/10.29303/jpft.v6i2.2073

\begin{abstract}
The research was conducted at the Laboratory of Material Mechanics, Department of Mechanical Engineering, Mataram University. The purpose of this research was to determined the effect of the Pack Carburizing parameters (temperature, soaking time and carburizer media composition) on the thickness of Calcium carbide layer $(\mathrm{CaC})$, which is formed on the surface of low carbon steel. The thickness of the calcium carbonate layer affects the surface hardness number of low carbon steel. This research used low carbon steel grade SS400 as the specimen. Carburizer media is a mixture of corncob charcoal powder and Pinctada maxima shells powder (PMSP). Packs Carburizing was carried out at various temperatures: $875^{\circ} \mathrm{C}, 900{ }^{\circ} \mathrm{C}$, soaking time: 1,2,3 hours and the percentage of PMSP on the carburizer media: 10\%, 20\%, 30\%. The results of the research show that the temperature carburizing, soaking time and the addition of PMSP affect the thickness of the calcium carbide layer on the surface of SS400 steel which is subjected to pack carburizing process. This is indicated by an increase in the surface hardness number of $421 \%$, the wear resistance 62,2\%. the thickness of the calcium carbide layer $1050 \mu \mathrm{m}$, the formation of pearlite structure, at the carburizing temperature of $900{ }^{\circ} \mathrm{C}$, soaking time 3 hours and $30 \%$ addition of PMSP.
\end{abstract}

Keywords: low carbon steel; pack carburizer; media carburize, pinctada maxima shell powder

\section{PENDAHULUAN}

Baja SS400 adalah termasuk baja karbon rendah yang biasa digunakan di industri pembuat alat-alat pertanian. Baja SS400 mempunyai kelebihan mudah dibentuk, tahan korosi dan keuletannya tinggi, kelemahannya angka kekerasan permukaannya rendah, mudah aus dan kekuatan tariknya rendah. Di industri pembuatan alat pertanian untuk mengkatkan angka kekerasan permukaan baja SS400 supaya tajam dilakukan dengan cara flame hardening dan pendinginan cepat dengan media air yang biasa disebut dengan proses penyepuhan. Proses penyepuhan mempunyai kelemahan angka kekerasan permukaan yang dihasilkan tidak terkontrol sehingga material baja SS400 yang mengalami proses penyepuhan cenderung getas, mudah aus dan umur pakainya (wear resistance) rendah. Idealnya angka kekerasan permukaanya tinggi, ulet, tahan aus sehingga umur pakainya lama. Metode untuk meningkatkan angka kekerasan baja karbon rendah telah lama dikembangkan, yaitu metode Pack Carburizing. Proses carburizing merupakan proses penambahan unsur karbon (C) ke bagian permukaan bahan dimana unsur karbon ini didapat dari bahan- bahan yang mengandung karbon sehingga kekerasan permukaan logam dapat meningkat tetapi dalamnya (core) tetap ulet. Untuk mempercepat proses maka ditambahkan barium karbonat (BaCO3), kalsium karbonat $(\mathrm{CaCO} 3)$ atau natrium karbonat $(\mathrm{NaCO} 3)$ sebagai energizer atau katalis yang dicampur dengan arang sebagai sumber karbon, dimasukkan ke dalam kotak karburasi dengan material yang dikarburasi kemudian dipanaskan pada dapur listrik pada temperatur carburing.. Pada proses pack carburizing media karburasi berupa 
arang yang dicampur dengan 10\%- $40 \%$ $\mathrm{CaCO}_{3}$ atau $\mathrm{BaCO}_{3}$. Baja dimasukkan ke dalam kotak karburasi yang sudah berisi media karburasi kemudian dipanaskan pada temperatur $850{ }^{\circ} \mathrm{C}-950{ }^{\circ} \mathrm{C}$ (Callister \& Rethwisch, 2014).

(Darmo et al., 2018) sendiri telah melakukan penelitian mengenai pengaruh proses pack carburizing terhadap perubahan angka kekerasan dan struktur mikro baja SS400. Media karburasi berupa campuran arang tempurung kelapa dan serbuk cangkang keong emas. Hasil dari penelitianya,angka kekerasan naik dari 142 $\mathrm{Kg} / \mathrm{mm}^{2}$ menjadi $262,30 \mathrm{Kg} / \mathrm{mm}^{2}$ setelah proses pack carburizing pada suhu $950{ }^{\circ} \mathrm{C}$, waktu karburasi 5 jam, prosentase penambahan, serbuk cangkang keong emas $30 \%$. Struktur mikro berubah dari ferrite menjadi pearlite, yang bersifat lebih keras. Sifat mekanik baja karbon rendah yang mengalami proses pack carburizing juga dipengaruhi oleh perlakuan panas lanjut (post heat treatment) (Priyadarshini et al., 2014). Penelitian dilakukan dengan menggunakan media carburizing karbon aktif ,dengan variasi suhu 850, 900 dan $950{ }^{\circ} \mathrm{C}$, dan waktu carburizing 15 dan 30 menit. Perlakuan panas lanjut dengan proses quenching di oli, ditempering pada suhu 550 ${ }^{0} \mathrm{C}$ dan diholding 60 menit. Kesimpulannya proses pack carburizing menurunkan energi impact (ketangguhan) baja karbon rendah dan ketangguhannya menurun dengan meningkatnya suhu carburizing. Sifat-sifat mekanik yang optimum di dapat pada kombinasi suhu carburizing $900{ }^{\circ} \mathrm{C}$, selama 30 menit dilanjutkan dengan proses quenching di oli ditempering pada suhu $550{ }^{\circ} \mathrm{C}$ dan waktu holding 60 menit.

Berdasarkan penelitian (Kuswanto, 2010) proses pack carburizing pada material baja karbon rendah pada temperatur $900^{\circ} \mathrm{C}$ dengan waktu karburasi 2 jam berpengaruh terhadap kekuatan yield baja karbon rendah. Hasilnya menunjukan bahwa tegangan tarik yield menjadi lebih tinggi dibanding sebelumnya. Teknik quenching juga berpengaruh pada sifat mekanik baja karbon rendah (Miernik et al., 2010). Berdasarkan hasil penelitiannya kombinasi terbaik sifat mekanik yang diperoleh untuk perlakuan panas yang terdiri dari heating suhu 900 ${ }^{\mathrm{O}} \mathrm{C}$, holding, cooling $\mathrm{d} u$ a fase dan cooling dalam air. Dengan perlakuan panas ini, terjadi peningkatan kekerasan, ketangguhan, tegangan Yield dan kekuatan tarik hampir dua kali lipat juga didukung oleh penelitan (Rijab, M. A., \& Al-mosawi, A. I. 2014).

Penelitian tentang efektifitas penggunaan karbon dari arang bambu, pelepah kelapa, tulang bebek dan tulang kambing sebagai sumber carburizer, telah dilakukan oleh (Ngakan \& Putra, 2016). Hasil penelitian menunjukkan bahwa carburizer dengan arang tulang kambing memberikan kekerasan permukaan yang paling tinggi $\left(556,37 \mathrm{Kg} / \mathrm{mm}^{2}\right)$.

\section{METODE PENELITIAN}

Metode penelitian yang digunakan penelitian eksperimental laboratorium dengan variabel penelitian antara lain: Variabel terikat: angka kekerasan permukaan, laju keausan dan ketebalan lapisan karburasi (calsium carbida). Variabel bebas: temperatur, waktu karburasi dan prosentase penambahan SCKM kedalam media karburasi. Variabel kontrol: dimensi spesimen, beban gesek, dan putaran roda penggesek.

Spesimen adalah baja karbon rendah type SS400. Dengan komposisi unsur: $\mathrm{Fe}=$ $97,86 \%, \mathrm{C}=0,168 \%, \mathrm{Mn}=0,756 \%, \mathrm{Si}=$ $0,159 \%, P=0,023 \%, S=0,014 \%$, dan sisanya unsur-unsur lain. Bentuk penampang spesimen persegi dengan ukuran $24 \times 18 \times 3,4$ $\mathrm{mm}^{3} \quad$ standar ASTM G99-95. Spesimen 
dimasukkan kedalam kotak karburasi, berisi media karburasi berupa campuran antara arang tongkol jagung dan serbuk cangkang kerang mutiara dengan variasi prosentase berat : 90\% : 10\%; 80\% : 20\%; 70\% ; 30\%. Kotak karburasi dimasukkan ke dapur pemanas dengan variasi suhu (875 dan 900 ${ }^{\circ} \mathrm{C}$ ) dan variasi waktu kaburasi (1, 2, 3 jam). Kemudian dilanjutkan dengan pengujian kekerasan permukaan dilakukan dengan alat uji kekerasan mikro menggunakan skala Vickers, dengan pembebanan $1 \mathrm{~kg}$ dan waktu pengujian selama 10 detik. Uji Keausan dilakukan dengan alat uji keausan abrasive, seperti Gambar 2. Alat ini menggunakan kurtas abrasif silikon karbida no. 800 , beban pengaus 200 gr, putaran disk $800 \mathrm{rpm}$, kecepatan geser spesimen 0,14 $\mathrm{m} /$ menit dan lama pengujian 30 detik.

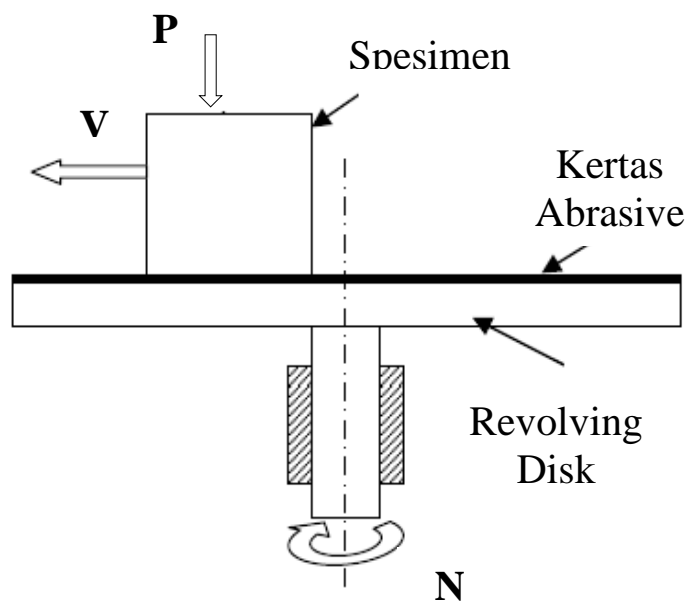

Gambar 1. Mekanisme alat uji keausan abrasif

Keterangan: $\mathrm{P}=$ beban pengausan $(\mathrm{Kg})$ $\mathrm{V}=$ kecepatan perpindahan specimen $(\mathrm{m} / \mathrm{s})$, $\mathrm{N}=$ putaran disk (rpm)

Laju keausan pada pengujian ini dinyatakan sebagai berkurangnya massa atau volume benda uji setelah mengalami penggesekan (abrasi akibat kontak antara disk yang berputar dan benda uji) tiap satuan waktu, yang dinyatakan dengan:

$$
\mathrm{W}=\frac{w}{s} \quad(\mathrm{mg} / \text { detik })
$$

Keterangan: $\mathrm{w}=$ berat materil yang hilang, $\mathrm{s}$ = waktu total pengujian (detik).

Selanjutnya pengamatan Struktur mikro lapisan calsium carbida pada permukaan spesimen dilakukan dengan menggunakan SEM-EDX Merk FEI, Type: Inspect-S50, etsa nital $2,5 \%$, pembesaran $100 x$

\section{HASIL DAN PEMBAHASAN}

\section{Hasil Pengujian Angka Kekerasan Permukaan Lapisan Calsium Carbida}

Hasil pengujian kekerasan lapisan karburasi pada suhu $875{ }^{0} \mathrm{C}$ dan $900{ }^{\circ} \mathrm{C}$ dengan variasi waktu pack carburizing 1,2, 3 jam dan variasi penambahan 10\%, 20\%, $30 \%$ SCKM ditampilkan seperti oleh Gambar 2.
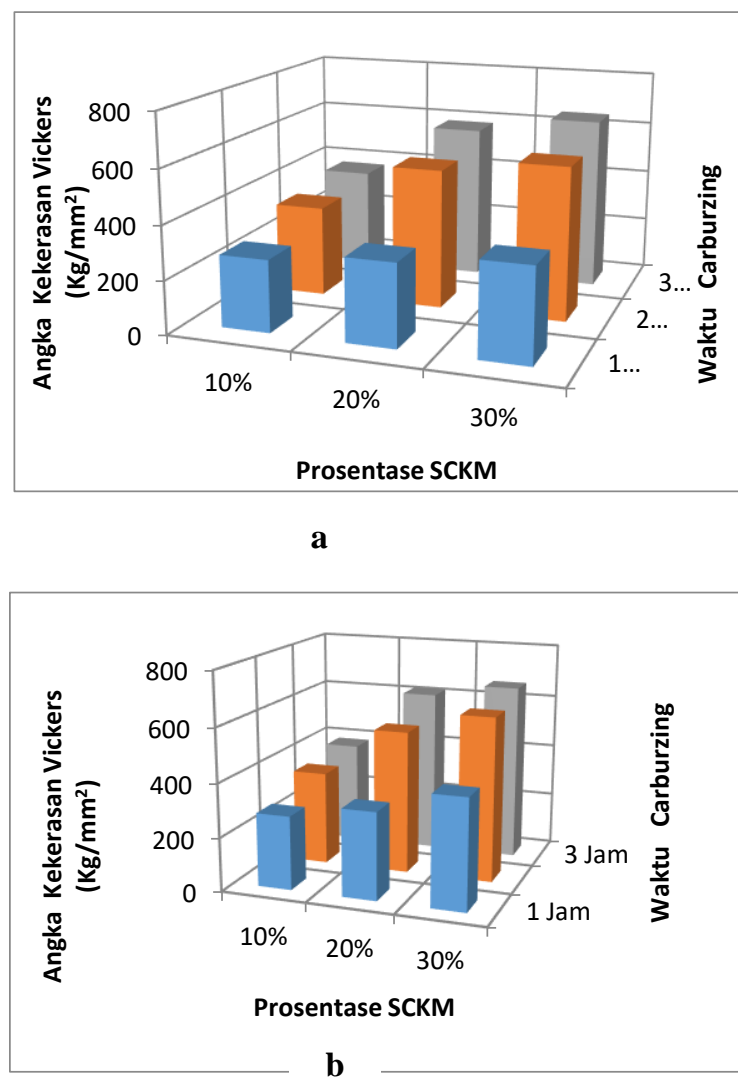

Gambar 2. Angka kekerasan lapisan calsium carbida pada proses pack carburizng a) Suhu $875{ }^{\circ} \mathrm{C}$. b) Suhu $900{ }^{\circ} \mathrm{C}$ 


\section{Hasil Pengujian Laju Keausan}

Hasil pengujian laju keausan dari spesimen yang mengalami perlakuan pack carburizing, ditunjukkan pada Gambar 3. pada suhu $875^{\circ} \mathrm{C}$ dan Gambar 4. .pada suhu $900{ }^{\circ} \mathrm{C}$

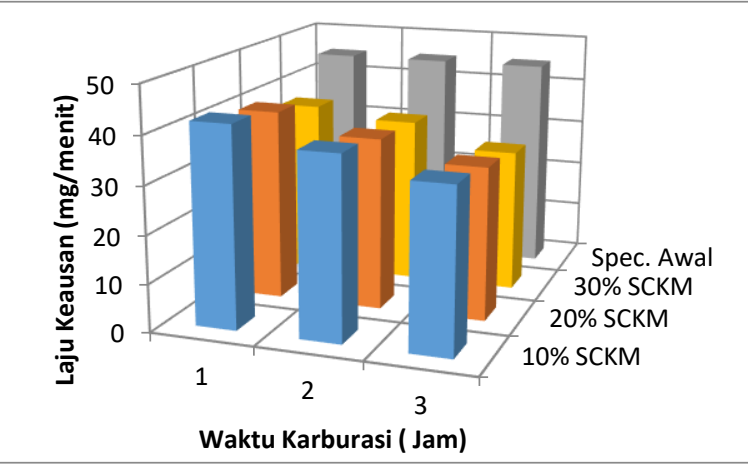

Gambar 3. Laju keausan pada permukaan spesimen pada pack carburizing pada suhu $875{ }^{\circ} \mathrm{C}$.

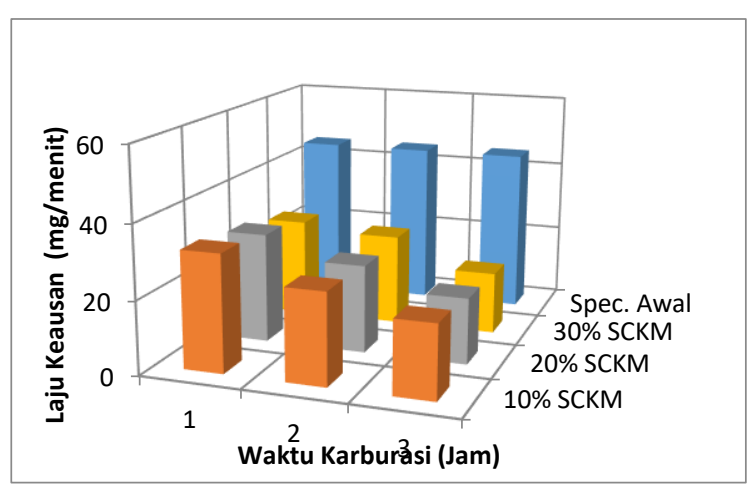

Gambar 4. Laju keausan pada permukaan spesimen pada pack carburizing pada suhu 900 ${ }^{0} \mathrm{C}$.

\section{Hasil Pengamatan Struktur Mikro Lapisan Calsium Carbida}

Hasil pengujian struktur mikro lapisan karburasi (kalsium karbida) pada permukaan dari spesimen setelah perlakuan pack carburizing ditunjukkan pada Gambar 5 . pada suhu $875^{\circ} \mathrm{C}$ dan Gambar 6. pada suhu $900{ }^{\circ} \mathrm{C}$

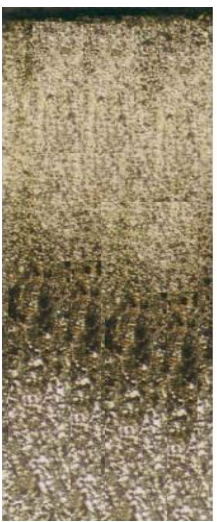

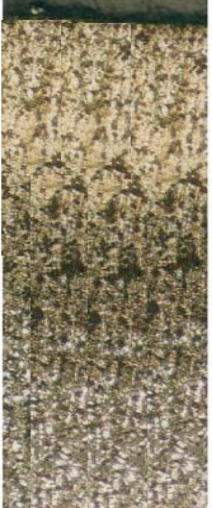

b

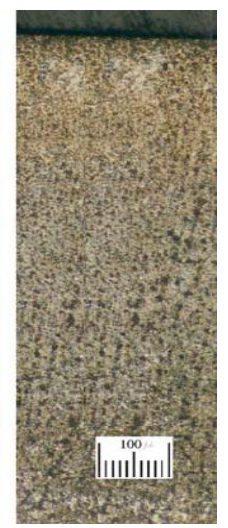

c
Gambar 5. Lapisan calsium carbida pada suhu pack carburizing $875^{\circ} \mathrm{C}$ waktu 3 jam, etsa nital 2,5\%, pembesaran 100x. a. Penambahan SCKM 10\%; b. Penambahan SCKM 20\%; c. Penambahan SCKM 30\%;

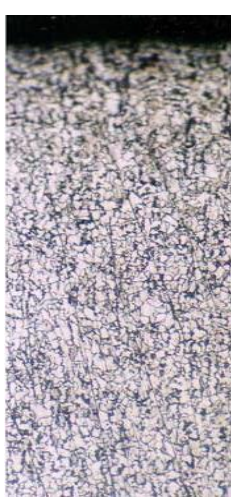

a

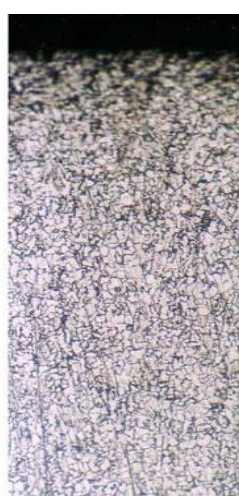

b

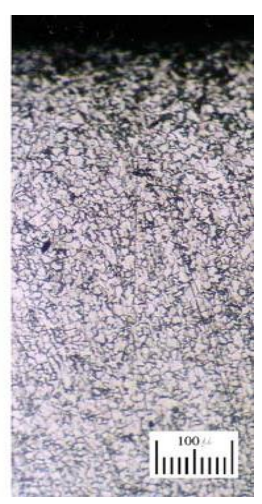

c
Gambar 6. Lapisan kalsium karbida pada suhu pack carburizing $900{ }^{\circ} \mathrm{C}$ waktu 3 jam, etsa nital $2,5 \%$, pembesaran 100x. a. Penambahan SCKM $10 \%$; b. Penambahan SCKM 20\%; c. Penambahan SCKM 30\%

\section{Pembahasan}

\section{Perubahan Angka Kekerasan Permukaan Lapisan Calsium Carbida}

Agar proses pack carburizing mengahasilkan kualitas lapisan karburasi yang baik biasanya ditambahkan $\mathrm{CaCO}_{3}$ atau $\mathrm{BaCO}_{3}$ pada media carburizer . Fungsinya, sebagai zat pengaktif karbon (energizer) agar unsur karbon lebih cepat terdifusi pada material yang dikarburasi. Pada penelitian ini digunakan serbuk cangkang kerang mutiara (SCKM) sebagai zat pengaktif karbon 
(energizer) dicampur dengan arang tongkol jagung. Variasi prosentase penambahan $10 \%$, 20\%, dan $30 \%$ berat dari media carburizer.

Secara umum terjadi perubahan angka kekerasan permukaan spesimen, yang mengindikasikan adanya lapisan senyawa lain. Berdasarkan hasil pengujian X-ray difraction karakteristiknya menyerupai senyawa calsium carbida $(\mathrm{CaC})$. Spesimen tanpa perlakuan pack carburizing (belum terdadapat lapisan $\mathrm{CaC}$ ) angka kekerasan permukaan nya adalah $127 \mathrm{Kg} / \mathrm{mm}^{2}$. Angka kekerasan permukaan lapisan calsium carbida pada proses pack carburizing suhu $875^{\circ} \mathrm{C}$ ( Gambar 2a.) terendah $270 \mathrm{Kg} / \mathrm{mm}^{2}$ (terjadi kenaikan $113 \%$ ) dihasilkan pada prosentase penambahan SCKM $10 \%$ waktu karburasi 1 jam, angka kekerasan permukaan tertinggi $650 \mathrm{Kg} / \mathrm{mm}^{2}$ (terjadi kenaikan $411 \%$ ) dihasilkan pada prosentase penambahan SCKM 30 \% waktu karburasi 3jam. Setelah melalui proses pack carburizing pada suhu $900{ }^{0} \mathrm{C}$ angka kekerasan permukaan lapisan calsium carbida semakin meningkat, seperti ditunjukkan pada Gambar 2b. Angka kekerasan permukaan terendah $275 \mathrm{Kg} / \mathrm{mm}^{2}$ (terjadi kenaikan $116 \%$ ) dan angka kekerasan permukaan tertinggi $662 \mathrm{Kg} / \mathrm{mm}^{2}$ (terjadi kenaikan $421 \%$ ) pada variasi waktu karburasi 1, 3 jam dengan variasi prosentase penambahan SCKM $10 \%$ dan 30\%.

\section{Perubahan Keausan Pada Permukaan Baja Karbon Rendah}

Pengujian keausan dilakukan pada permukaan baja karbon rendah yang telah melalui proses pack carburizing. Pengujian raw material (tanpa perlakuan pack carburizing) didapatkan kecepatan abrasi atau laju keausan sebesar $45 \mathrm{mg} / \mathrm{menit}$. Uji keausan pada permukaan baja karbon rendah yang telah melalui proses pack carburizing, suhu $875{ }^{\circ} \mathrm{C}$ karburasi dengan penambahan serbuk cangkang kerang mutiara (SCKM) $10 \%$, 20\%, dan $30 \%$ berturut-turut memberikan laju keausan sebesar 42 $\mathrm{mg} / \mathrm{menit}$, $40 \mathrm{mg} / \mathrm{menit}, 37 \mathrm{mg} / \mathrm{menit}$, untuk waktu karburasi 1 jam, waktu karburasi 2 jam : $38 \mathrm{mg} / \mathrm{menit}, 36 \mathrm{mg} / \mathrm{menit}, 35$ mg/menit dan waktu karburasi 3 jam : 34 $\mathrm{mg} / \mathrm{menit}, \quad 32 \mathrm{mg} / \mathrm{menit}, \quad 30$ $\mathrm{mg} / \mathrm{menit}$.(Gambar 3.). Laju keausan terendah diperoleh pada penambahan SCKM pada media karburasi sebesar $30 \%$, waktu karburasi 3 menit, laju keausan yang terjadi sebesar $30 \mathrm{mg} / \mathrm{menit}$ atau peningkatan ketahanan terhadap keausan sebesar 33,3\%. Uji keausan pada permukaan baja karbon rendah yang telah melalui proses pack carburizing karburasi suhu $900{ }^{\circ} \mathrm{C}$ dengan penambahan SCKM: 10\%, 20\%, dan 30\% berturut-turut memberikan laju keausan sebesar $32 \mathrm{mg} / \mathrm{menit}, 30 \mathrm{mg} / \mathrm{menit}, 27$ $\mathrm{mg} / \mathrm{menit}$, untuk waktu karburasi 1 jam, waktu karburasi 2 jam : $25 \mathrm{mg} /$ menit, 24 $\mathrm{mg} / \mathrm{menit}, 20 \mathrm{mg} / \mathrm{menit}$ dan waktu karburasi 3 jam : $20 \mathrm{mg} / \mathrm{menit}, 18 \mathrm{mg} / \mathrm{menit}, 17$ $\mathrm{mg} / \mathrm{menit}$ (Gambar 4.). Pada proses pack carburizing karburasi suhu $900{ }^{\circ} \mathrm{C}$, waktu 3 Jam, penambahan SCKM pada media karburasi tidak begitu berpengaruh pada laju keausan, hanya selisih $1 \mathrm{mg} / \mathrm{menit}$. Laju keausan terendah diperoleh pada penambahan SCKM pada media karburasi sebesar 30\%, waktu karburasi 3 menit, laju keausan yang terjadi sebesar $17 \mathrm{mg} / \mathrm{menit}$ atau peningkatan ketahanan terhadap keausan sebesar 62, $2 \%$.

\section{Struktur Mikro Lapisan Calsium Carbida}

Pengamatan Struktur mikro lapisan calsium carbida pada permukaan spesimen dilakukan dengan menggunakan SEM-EDX Merk FEI, Type: Inspect-S50, etsa nital 2,5\%, pembesaran 100 kali. Pengamatan dilakukan pada waktu pack carburizing yang optimum, yaitu waktu 3 jam. Setelah 
mengalami perlakukan pack carburizing maka tampak bahwa ketebalan lapisan calsium carbida pada permukaan baja karbon rendah meningkat dengan indikasi meningkatnya angka kekerasan permukaan. Peningkatan ketebalan calsium carbida sebanding dengan kenaikan prosentase SCKM pada media karburasi. Gambar 5. menunjukkan perubahan ketebalan lapisan calsium carbida akibat perubahan prosentase SCKM pada media karburasi, pada proses pack carburizing temperatur $850^{\circ} \mathrm{C}$, waktu karburasi 3 jam. Berdasarkan pengukuan dengan menggunakan digital mikrometer ketebalan lapisan calsium carbida adalah $450 \mu \mathrm{m}$ pada prosentase penambahan SCKM $10 \%, 850 \mu \mathrm{m}$ dan 920 $\mu \mathrm{m}$ masing masing pada prosentase penambahan SCKM $20 \%$ dan $30 \%$. Selanjtnya pada proses pack carburizing pada temperatur $900^{\circ} \mathrm{C}$ waktu karburasi 3 jam, ketebalan lapisan calsium carbida yang terbentuk semakin tebal/dalam, seperti terlihat pada Gambar 6 . Ketebalan lapisan calsium carbida adalah $550 \mu \mathrm{m}, 950 \mu \mathrm{m}$ dan $1050 \mu \mathrm{m}$, masing- masing pada prosentase penambahan SCKM 10\%, 20\% dan 30\%. Perubahan ketebalan lapisan calsium carbida ini yang menyebabkan angka kekerasan permukaan naik sehingga keatahanan aus meningkat atau kelajuan aus/abrasi menurun.

Fenomena ini diduga karena kalsium oksida yang terkandung dalam SCKM pada suhu tinggi (suhu proses pack carburizing) bereaksi dengan atom karbon dari arang tongkol jagung sehingga membentuk lapisan calsium karbida pada permukaan baja karbon rendah (spesimen), dengan persamaan reaksi sebagai berikut : (Oyetunji, 2012):

$$
\begin{aligned}
& \mathrm{CaCO}_{3}+3 \mathrm{C} \longrightarrow \mathrm{CaC}_{2}+\mathrm{CO}_{2}+\mathrm{CO} \\
& \mathrm{CaC}_{2}+\mathrm{O}_{2} \longrightarrow \mathrm{CaC}+\mathrm{CO}_{2}
\end{aligned}
$$

$\mathrm{Fe}+\mathrm{CaC}_{2}+\mathrm{C}+\mathrm{O}_{2} \longrightarrow \mathrm{Fe}+\mathrm{CaC}+2 \mathrm{CO}$

Berdasarkan reaksi diatas tampak bahwa unsur kalsium menyerap atom karbon dari arang sehingga semakin lama (waktu karburasi bertambah) dapat menurunkan jumlah atom karbon aktif sampai terbentuk lapisan calsium carbida dengan ketebalan maksimal. Fenomena ini didukung oleh hasil penelitian (Rai, P. K. 2016). bahwa penambahan calsium karbonat sebesar $20 \%$ berat pada suhu karburasi $900^{\circ} \mathrm{C}$ memberikan kekerasan permukaan yang lebih baik yaitu sebesar $650 \mathrm{~kg} / \mathrm{mm}^{2}$ dibandingkan penambahan calsium karbonat sebesar $10 \%$ pada arang kayu pada suhu $925^{\circ} \mathrm{C}$ (memberikan kekerasan permukaan sebesar $475 \mathrm{~kg} / \mathrm{mm}^{2}$ ) dengan waktu karburasi 3 jam..

\section{PENUTUP}

Penambahan serbuk cangkang kerang mutiara pada media karburasi, berpengaruh pada perubahan angka kekerasan permukaan ,laju keausan, ketebalan lapisan calsium carbida dan perubahan struktur mikro pada spesimen baja karbon renda SS400 yang mengalami perlakuan panas pack carburizing . Angka kekerasan permukaan lapisan calsium carbida pada proses pack carburizing suhu $875^{\circ} \mathrm{C}$ terendah 270 $\mathrm{Kg} / \mathrm{mm}^{2}$ (terjadi kenaikan $113 \%$ ) dihasilkan pada prosentase penambahan SCKM $10 \%$ waktu karburasi 1 jam, tertinggi angka kekerasan permukaan tertinggi $662 \mathrm{Kg} / \mathrm{mm}^{2}$ (terjadi kenaikan $421 \%$ ) pada suhu $900{ }^{\circ} \mathrm{C}$ waktu karburasi 3 jam, 30\%.

Laju keausan terendah sebesar 17 $\mathrm{mg} / \mathrm{menit}$ atau terjadi peningkatan ketahanan terhadap keausan sebesar 62, $2 \%$ suhu 900 ${ }^{0} \mathrm{C}$, waktu karburasi 3 jam, penambahan SCKM pada media karburasi 30\% . Pada kondisi yang sama didapatkan hasil ketebalan lapisan calsium carbida 
maksimal yaitu $1050 \mu \mathrm{m}$, dan struktur pearlite yang terbentuk semakin banyak.

\section{UCAPAN TERIMAKASIH}

Ucapan terima kasih disampaikan kepada Tim Peneliti Bidang Keahlian Mekanika Material Jurusan Teknik Mesin Unram dan LPPM Unram.

\section{REFERENSI}

Callister, W. D., \& Rethwisch, D. G. (2014). Materials Science and Engineering 9th Edition. In Computing in Science \& Engineering. https://doi.org/10.1016/j.str.2011.03.0 05

Darmo, S., Soenoko, R., Siswanto, E., \& Widodo, T. D. (2018). Study pack carburizing for subsoil plow chisel with alternative carburizer media corn cob charcoal-pictada maxima shell powder. International Journal of Mechanical Engineering and Technology.

Kuswanto, B. (2010). Pengaruh Perbedaan Ukuran Butir Arang Tempurung Kelapa-Barium Karbonat Terhadap Peningkatan Kekerasan Permukaan Material Baja St 37 dengan Proses Pack Carburizing. Diponegoro University.

Miernik, K., Bogucki, R., \& Pytel, S. (2010). Effect of quenching techniques on the mechanical properties of low carbon structural steel. Archives Of Foundry Engineering.

Ngakan, D., \& Putra, K. (2016). EfektifitasCarburizer dari Sumber Karbon Berbeda Pada Proses Pack Carburizing. Jurnal METTEK.

Oyetunji. (2012). Effects of Carburizing Process Variables on Mechanical and Chemical Properties of Carburized Mild Steel. Journal of Basic \& Applied Sciences. https://doi.org/10.6000/19275129.2012.08.02.11

Priyadarshini, S., Sharma, T., \& Arora, G. (2014). Effect of Post Carburizing
Treatment on Hardness of Low Carbon Steel. International Journal of Advanced Mechanical Engineering.

Rai, P. K. (2016). Study on Mechanical Properties of Carburized Mild Steel Subjected to Heat Treatment. International Journal of Engineering Technology and Computer Research (IJETCR), 4(1), 83-87.

Rijab, M. A., \& Al-mosawi, A. I. (2014). Effect of carburizing on fatigue strength. In 3rd International Scientific Conference F.T.E.

Roy, S., \& Sundararajan, S. (2016). Surface $\&$ Coatings Technology The effect of heat treatment routes on the retained austenite and Tribomechanical properties of carburized AISI 8620 steel. Surface \& Coatings Technology, 308, 236-243. https://doi.org/10.1016/j.surfcoat.2016. 06.095 